\title{
Anaphylatoxin C3a: A potential biomarker for esophageal cancer diagnosis
}

\author{
XU ZHANG and LINGZHI SUN \\ School of Pharmacy, Yancheng Teachers University, Yancheng, Jiangsu 224002, P.R. China
}

Received June 13, 2017; Accepted November 28, 2017

DOI: $10.3892 / \mathrm{mco} .2017 .1524$

\begin{abstract}
Esophageal carcinoma is a common malignancy worldwide, with a low 5-year survival rate. As the majority of cases are diagnosed at an advanced stage, there is an urgent need for an effective biomarker for early diagnosis of esophageal cancer patients. Surface-enhanced laser desorption ionization time-of-flight mass spectrometry (SELDI-TOF-MS) was applied to detect the serum protein expression in esophageal cancer patients using ProteinChip software, and the results were analyzed and screened using Biomarker Patterns and SPSS16.0 software. The ELISA method was conducted to determine the concentration of anaphylatoxin $\mathrm{C} 3 \mathrm{a}$, which is one of the complement proteins, in the serum of esophageal cancer patients and non-esophageal cancer participants. A total of 144 effective differential expression protein peaks in the window of $1-10 \mathrm{kDa}$ were obtained $(\mathrm{P}<0.05) . \mathrm{M} / \mathrm{Z}$ $8,926.478\left(\mathrm{P}<10^{-6}\right)$ protein peak was employed as the diagnostic biomarker for esophageal carcinoma. This established diagnostic biomarker has a sensitivity of 95\% (19/20) and an accuracy of $100 \%$ (19/19) for positive prediction. The results suggested that anaphylatoxin $\mathrm{C} 3$ a may be a promising biomarker in the diagnosis of esophageal carcinoma, and may play a key role in promoting esophageal carcinogenesis.
\end{abstract}

\section{Introduction}

Esophageal carcinoma is a common malignancy worldwide, with a 5-year survival rate of $\sim 30 \%$, even with chemotherapy, surgery and radiation therapy, due to tumor heterogeneity (1-9). It is well-known that early diagnosis and timely treatment may improve the survival rate in early-stage cancer patients, with a 5-year survival rate as high as $90 \%(10,11)$. Cancer Research UK

Correspondence to: Dr Lingzhi Sun, School of Pharmacy, Yancheng Teachers University, 50 Kaifang Avenue, Yancheng, Jiangsu 224002, P.R. China

E-mail: sunlz@yctu.edu.cn

Key words: esophageal carcinoma, surface-enhanced laser desorption ionization time-of-flight mass spectrometry, anaphylatoxin $\mathrm{C} 3 \mathrm{a}$, diagnostic biomarker, tumor heterogeneity, immune escape (http://www.cancerresearchuk.org/about-cancer/cancer-symptoms/why-is-early-diagnosis-important) clearly reported the association of survival rate with stage at diagnosis for several cancers, such as breast, ovarian, lung and bowel cancer. However, the majority of esophageal cancer patients are often diagnosed at an advanced stage, as there are no obvious symptoms in the early stages of the disease. Therefore, it is crucial to identify an effective biomarker for early diagnosis. Recently, the matrix-assisted laser desorption/ionization time-of-flight mass spectrometry (MOLDI-TOF-MS) and surface-enhanced laser desorption/ionization time-of-flight mass spectrometry (SELDI-TOF-MS) techniques have been widely employed in the search for cancer biomarkers in brain cancer (12), oral squamous cell carcinoma (13), pancreatic cancer (14), lung cancer (15), esophageal squamous cell carcinoma (16) and breast cancer $(17,18)$, among others. There have been several attempts to identify esophageal carcinoma biomarkers using these techniques $(16,19-22)$. However, those studies failed to identify any single biomarker for the diagnosis of esophageal cancer, but rather indicated several proteins. In addition, the identified proteins differed among different research groups. This makes it difficult to establish a unified standard for rapid and accurate diagnosis of this type of cancer. In the present study, a single protein, anaphylatoxin $\mathrm{C} 3 \mathrm{a}$, which is one of the complement proteins, was investigated as a diagnostic biomarker to distinguish between esophageal cancer patients and healthy individuals.

\section{Materials and methods}

Research subjects. A total of 40 serum samples were included in this study, 20 of which were collected from esophageal carcinoma patients from Yancheng First People's Hospital (group A), whereas the others were collected from non-esophageal carcinoma participants recruited from the First Hospital of Nanjing Medical University (group B) between November 2014 and May 2015. The participants were aged 25-76 years, with a mean age of 55.7 years. In group A, there were 8 cases of patients who were undergoing therapy. All the blood collections were performed an overnight fast. Blood was collected in 5-ml blood collection tubes without anticoagulant and the serum samples were stored at $-80^{\circ} \mathrm{C}$ for further use.

Ethics statement. All patients signed an informed consent form and the study protocol was approved by the Institutional 


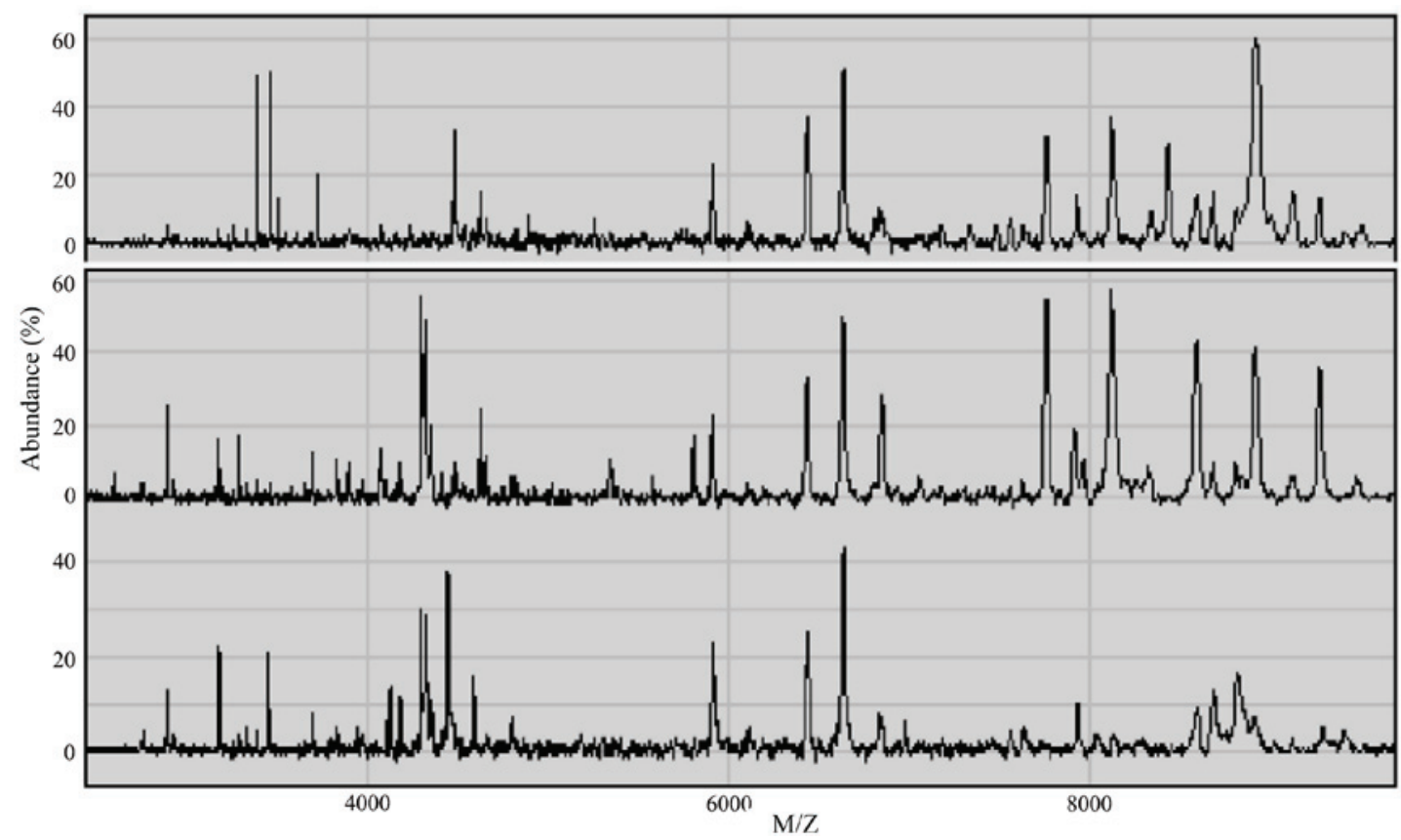

Figure 1. Protein mass spectrum peaks in the sera of esophageal cancer patients prior to treatment (upper) and after treatment (middle), and of non-esophageal carcinoma participants (bottom).

Review Board of the First People's Hospital of Yancheng (Yancheng, China). The study was reviewed and approved by Yancheng Medical Ethics Committee.

SELDI-TOF-MS assay. SELDI-TOF-MS (Ciphergen Biosystems, Fremont, CA, USA) was applied to collect the raw mass spectrometry data. Biomarker Wizard software (Ciphergen Biosystems, Fremont, CA, USA) was used to export the raw data into a digital format, according to the standard Excel format. A t-test was conducted with the Excel data using SPSS 17.0 software (SPSS Inc., Chicago, IL, USA).

Enzyme-linked immunoabsorbent assay (ELISA). The concentrations of $\mathrm{C} 3 \mathrm{a}$ in the serum samples were quantified by ELISA according to the manufacturer's protocol (cat. no. ab133037; Abcam, Cambridge, MA, USA). Briefly, $50 \mu 1$ standard samples and $50 \mu 1$ serum samples were diluted 5 times with phosphate-buffered saline, placed into a 96-well plate and cultured at $37^{\circ} \mathrm{C}$ for $30 \mathrm{~min}$. The plate was washed 5 times, after which time $50 \mu \mathrm{l}$ reagent A was added into each well, followed by $50 \mu 1$ reagent B. The samples were mixed well and cultured for a further $15 \mathrm{~min}$ at $37^{\circ} \mathrm{C}$ in the dark; stop solution was then added into each well. An ELISA plate reader (Synergy HXT; BioTek Instruments Inc., Winooski, VT, USA) was used at a wavelength of $450 \mathrm{~nm}$; the inter-assay and intra-assay coefficients of variation of the ELISA kits for C3a were $<10 \%$.

Statistical analysis. The SPSS 19.0 software package (SPSS Inc., Chicago, IL, USA) was used for data analysis, and the data are expressed as means \pm standard deviation. The comparison between the groups was performed using one-way analysis of variance. $\mathrm{P}<0.05$ indicates that the difference was statistically significant.
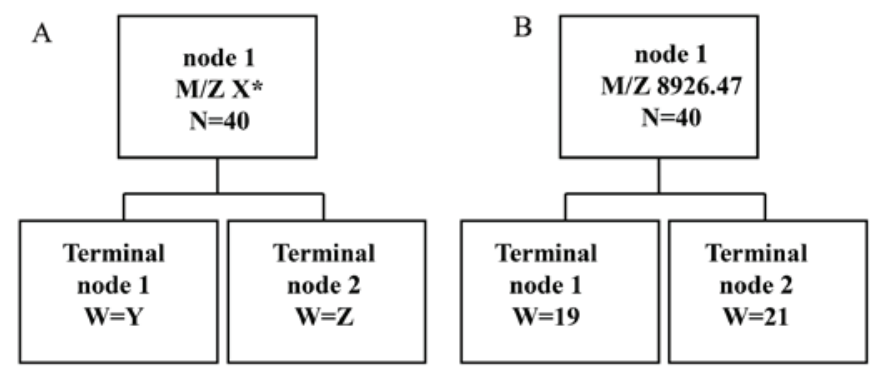

Figure 2. (A) The classical tree model; (B) the predicted results of M/Z $8,926.47$.

\section{Results}

Serum proteomic profiles. SELDI-TOF-MS was applied to examine the serum samples within a window of 1-10 kDa, and 253 protein peaks were detected in the sera of esophageal cancer patients. There were 144 statistically significant difference peaks $(\mathrm{P}<0.05)$ : 56 peaks had higher protein expression and 88 had lower protein expression in esophageal cancer patients. The mass spectra (MS) of the serum proteins of esophageal cancer patients and non-esophageal cancer participants are shown in Fig. 1.

Establishment of diagnostic biomarker. In order to establish the diagnostic biomarker, 6 MS peaks, i.e., M/Z 2,748.87 $\left(\mathrm{P}=2.38 \times 10^{-7}\right), \mathrm{M} / \mathrm{Z} 4,119.31\left(\mathrm{P}=3.18 \times 10^{-7}\right), \mathrm{M} / \mathrm{Z} 4,425.94$ $\left(\mathrm{P}=2.38 \times 10^{-7}\right), \mathrm{M} / \mathrm{Z} 4,798.62\left(\mathrm{P}=3.67 \times 10^{-7}\right), \mathrm{M} / \mathrm{Z}$ 9,136.76 $\left(\mathrm{P}=6.45 \times 10^{-7}\right)$ and $\mathrm{M} / \mathrm{Z} 8,926.47\left(\mathrm{P}=7.33 \times 10^{-8}\right)$, exhibiting statistically significant differences, were further analyzed. The classical tree model was employed to examine the predictor variables (Fig. 2A). The protein M/Z 8,926.47 had the best prediction result (Fig. 2B). The sensitivity and specificity of 


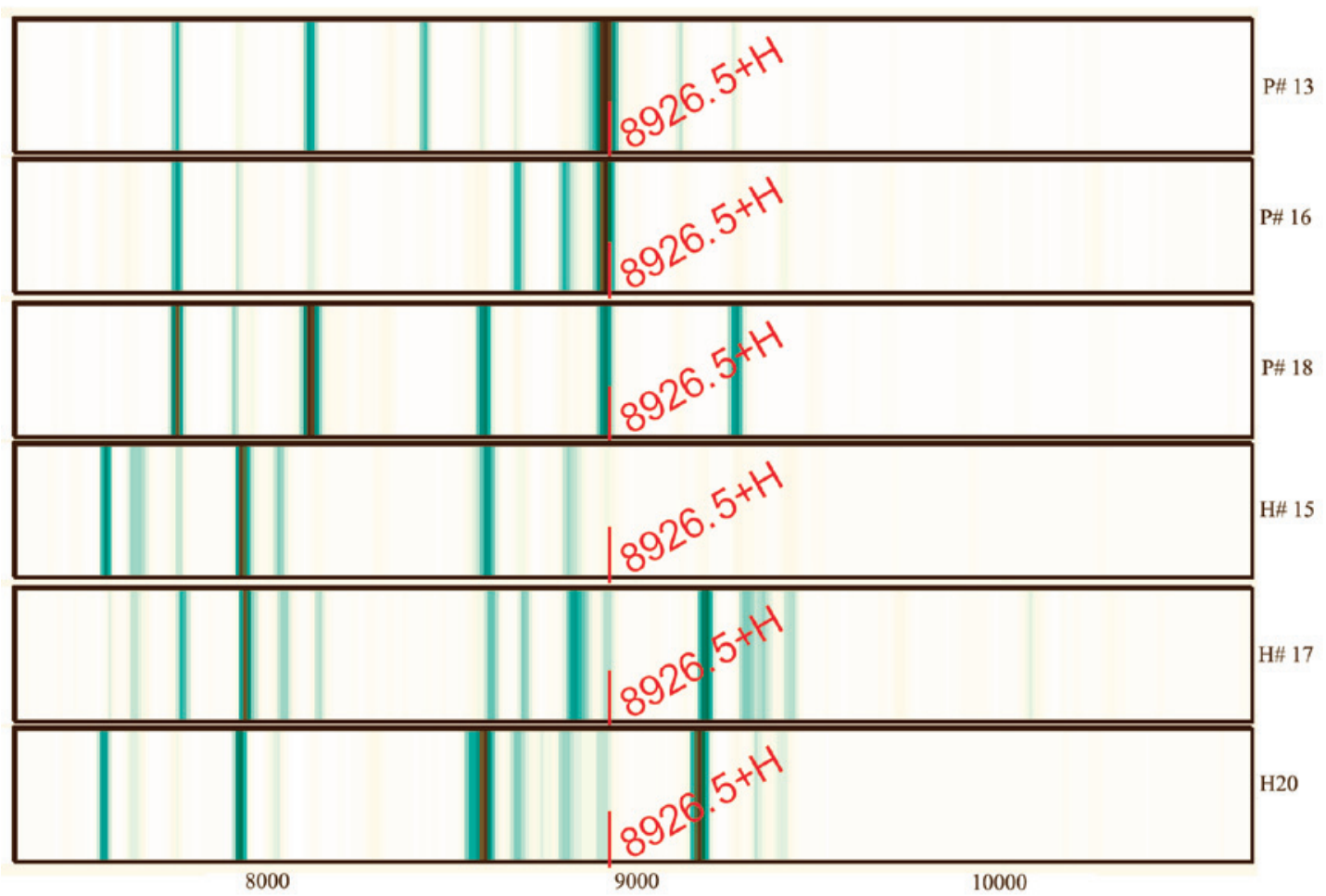

Figure 3. Serum protein mass spectra. Upper three, esophageal carcinoma patients (P); bottom three, non-esophageal carcinoma participants (healthy; H).
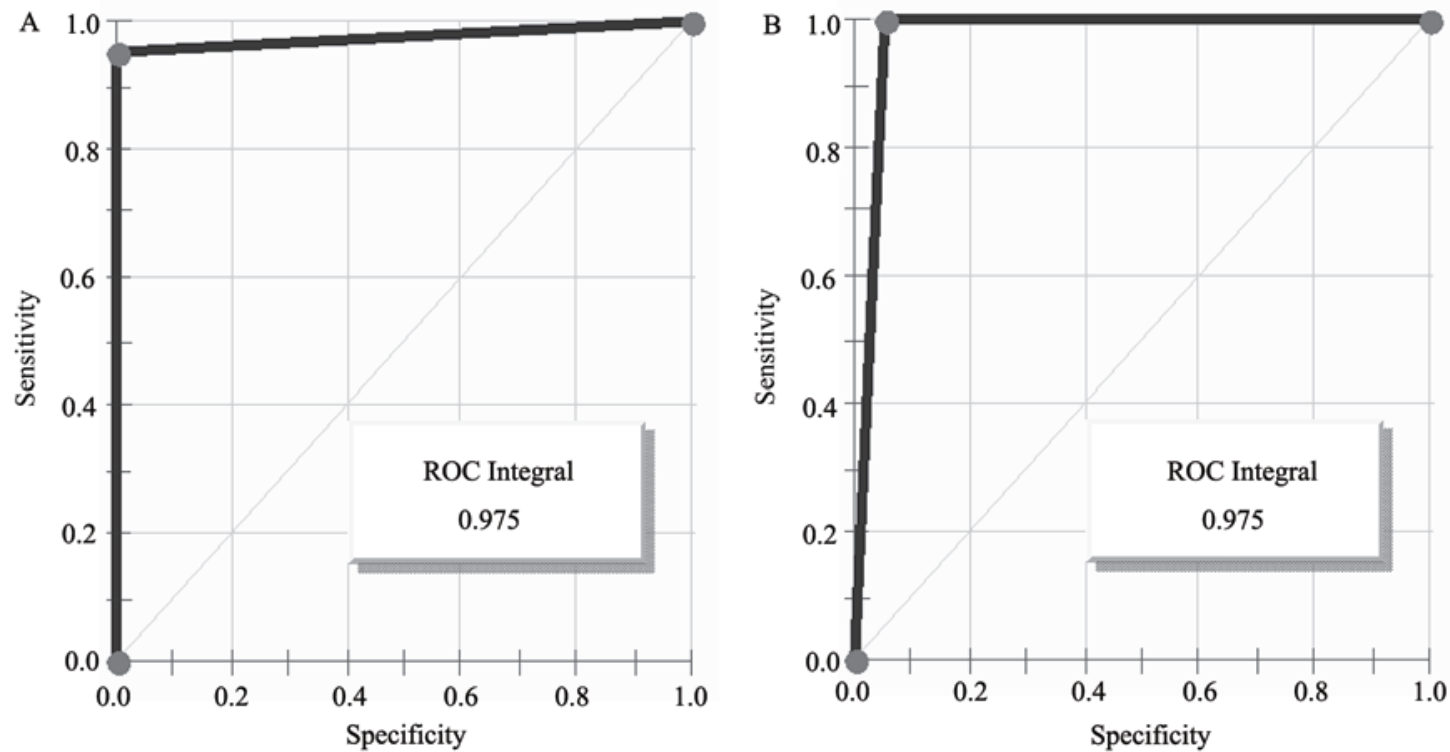

Figure 4. Receiver operating characteristics (ROC) curves of diagnostic biomarker. (A) ROC curve of diagnostic biomarker of patients; (B) ROC curve of diagnostic biomarker of non-esophageal carcinoma participants.

the biomarker were 95\% (19/20) and 97.5\% (39/40), respectively. The positive predictive accuracy was $100 \%(19 / 19)$ and the negative predictive accuracy was $95.2 \%$ (20/21). Thus, the protein at M/Z 8,926.47 may be an optimal biomarker for distinguishing the esophageal cancer and non-esophageal cancer sera with high accuracy and high specificity.

Further study indicated that the abundance of M/Z 8,926.47 was reduced from 60.69 prior to therapy to 43.39 after therapy (the mean abundance of this peak was 6.81 for non-esophageal carcinoma participants). Three of the serum protein MS of esophageal cancer patients and non-esophageal carcinoma participants are shown in Fig. 3. The intensities of $M / Z$ $8,926.47$ in the non-esophageal carcinoma participants were distinctly lower compared with those in esophageal carcinoma patients. The areas under the receiver operating characteristic curves of the diagnostic biomarker were $97.5 \%$ (Fig. 4).

Determination of the concentration of C3a via ELISA. The human C3a ELISA kit was used to determine the concentration of anaphylatoxin $\mathrm{C} 3 \mathrm{a}$ using the obtained serum samples. 


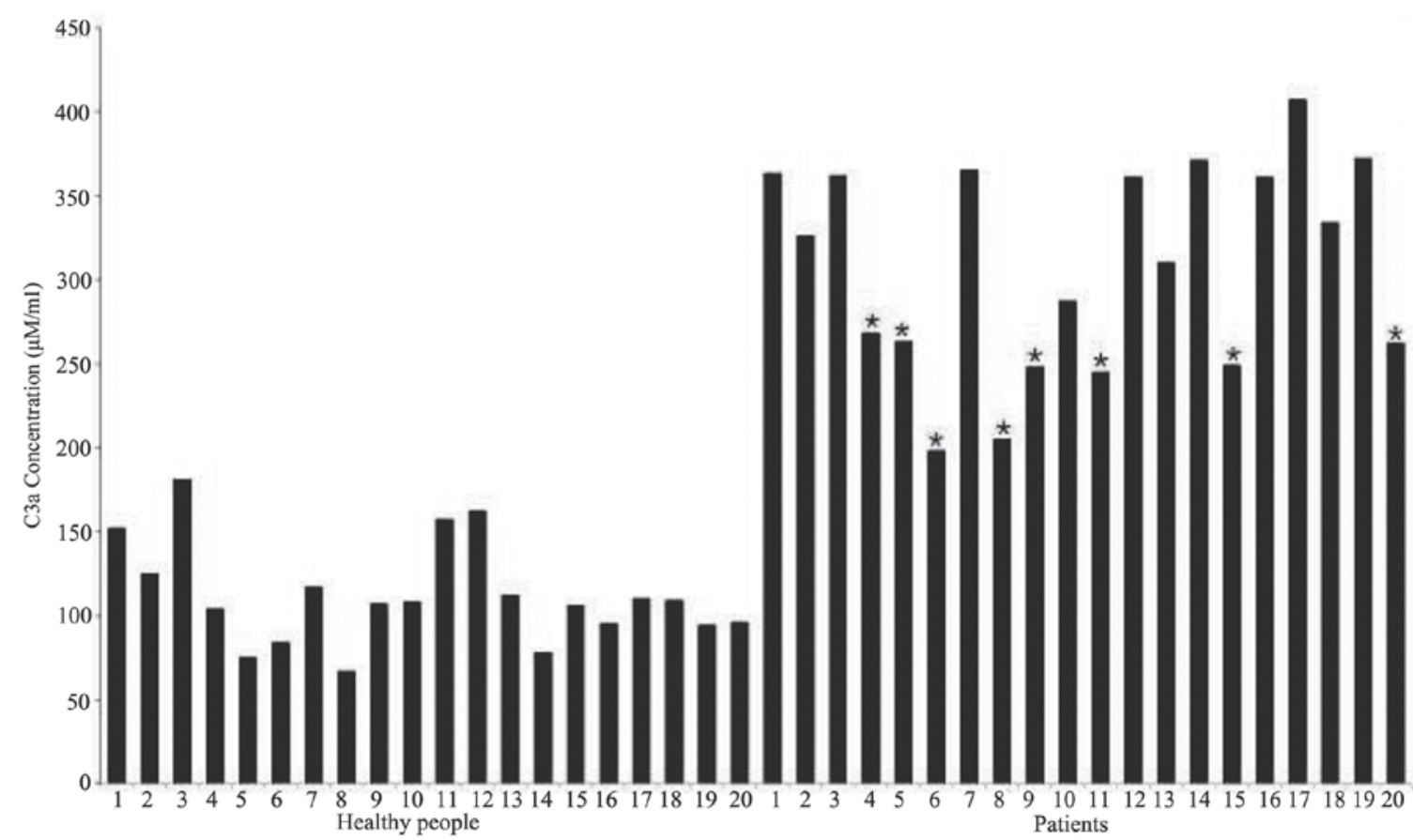

Figure 5. Concentrations of C3a in different serum samples determined by ELISA. The first 20 bars represent the C3a concentrations in healthy participants, whereas the remaining bars represent those in esophageal cancer patients $(\mathrm{P}<0.01)$. "sera from esophageal carcinoma patients undergoing chemotherapy and surgery.

The ELISA experimental results (Fig. 5) revealed that the concentration of anaphylatoxin $\mathrm{C} 3 \mathrm{a}$ in the sera of esophageal cancer patients (mean, $308 \pm 60 \mathrm{ng} / \mathrm{ml}$ ) were significantly higher compared with those in healthy participants (mean, $112 \pm 30 \mathrm{ng} / \mathrm{ml}$ ). Among esophageal carcinoma patients, the mean concentration of $\mathrm{C} 3 \mathrm{a}$ in the sera of those without therapy and those undergoing therapy was $352 \pm 31$ and $242 \pm 25 \mathrm{ng} / \mathrm{ml}$, respectively.

\section{Discussion}

Regarding the SELDI-TOF MS results, significant differences were observed in the serum samples between the esophageal carcinoma patients and healthy participants for 6 protein peaks $\left(\mathrm{P}<10^{-6}\right)$. Among those, the abundance of the peak M/Z 8,926.47 $\left(\mathrm{P}=7.33 \times 10^{-8}\right)$ markedly increased from 6.81 (non-esophageal carcinoma) to 60.69 (esophageal carcinoma), suggesting that the expression of $M / Z 8,926.47$ was significantly increased in the plasma of esophageal carcinoma patients. This particular peak distinguished between the sera of esophageal carcinoma patients and non-esophageal carcinoma participants with high accuracy $(100 \%)$ and high efficiency (97.5\%), indicating that $M / Z 8,926.47$ may be a promising biomarker for early diagnosis. Based on our experience, this peak is likely to be complementary to the $\mathrm{C} 3$ a protein.

The ELISA results demonstrated that the concentrations were statistically significantly different $(\mathrm{P}<0.01)$ and the mean concentration of anaphylatoxin $\mathrm{C} 3 \mathrm{a}$ in esophageal carcinoma and non-esophageal carcinoma samples was $308 \pm 60$ and $112 \pm 30 \mathrm{ng} / \mathrm{ml}$, respectively, which was in agreement with the MS peak abundance of 53.98 and 6.81 . Furthermore, among esophageal cancer samples, the $\mathrm{C} 3 \mathrm{a}$ concentration was $352 \pm 31$ and $242 \pm 25 \mathrm{ng} / \mathrm{ml}$ for samples before and after treatment, respectively, which was also in agreement with the MS peak abundances of 60.69 and 43.39. This finding indicates that, after treatment, the concentration of C3a in the plasma was markedly decreased. According to the ELISA results, it may be concluded that, when the serum $\mathrm{C} 3$ a concentration is $>120 \mathrm{ng} / \mathrm{ml}$, the risk of esophageal cancer is increased.

C3a is a serum protein first discovered in 1896, which plays a key role in either antitumor immune response (23-27), or in promoting tumor growth and progression $(28,29)$. However, the role of $\mathrm{C} 3 \mathrm{a}$ in esophageal cancer has not been determined to date. According to the MS and ELISA results, the anaphylatoxin $\mathrm{C} 3 \mathrm{a}$ concentrations in the sera of treated patients are significantly lower compared with those without treatment. It may be hypothesized that C3a plays a key role in promoting esophageal tumorigenesis. As previously reported, anaphylatoxin $\mathrm{C} 3 \mathrm{a}$ may contribute to cancer cell immune escape via promoting local immunosuppression $(30,31)$. However, more studies should be conducted to elucidate the mechanisms through which $\mathrm{C} 3 \mathrm{a}$ promotes esophageal tumorigenesis.

\section{Acknowledgements}

The authors would like to acknowledge the Department of Human Resources and Social Security of Jiangsu Province (swyy-030) and Foundation of Jiangsu Educational Committee (16KJB180031) for financially supporting the present study. Esophageal carcinoma serum samples were provided by Dr Zhou Xiaoning (Oncology Department, Yancheng First People's Hospital). Healthy participants' serum samples were provided by Dr Shao Qianwen (Oncology Department, the First Hospital of Nanjing Medical University). 


\section{References}

1. Fisher R, Pusztai L and Swanton C: Cancer heterogeneity: Implications for targeted therapeutics. Br J Cancer 108: 479-485, 2013.

2. Graff BA, Kvinnsland Y, Skretting A and Rofstad EK Intratumour heterogeneity in the uptake of macromolecular therapeutic agents in human melanoma xenografts. Br J Cancer 88 291-297, 2003.

3. Kim JH, Ko ES, Lim Y, Lee KS, Han BK, Ko EY, Hahn SY and Nam SJ: Breast cancer heterogeneity: MR imaging texture analysis and survival outcomes. Radiology 282: 665-675, 2017.

4. Beca F and Polyak K: Intratumor heterogeneity in breast cancer. Adv Exp Med Biol 882: 169-189, 2016.

5. Aleskandarany MA, Green AR, Ashankyty I, Elmouna A, Diez-Rodriguez M, Nolan CC, Ellis IO and Rakha EA: Impact of intratumoural heterogeneity on the assessment of Ki67 expression in breast cancer. Breast Cancer Res Treat 158 287-295, 2016

6. Suda K, Murakami I, Sakai K, Tomizawa K, Mizuuchi H, Sato K, Nishio K and Mitsudomi T: Heterogeneity in resistance mechanisms causes shorter duration of epidermal growth factor receptor kinase inhibitor treatment in lung cancer. Lung Cancer 91: 36-40, 2016.

7. Bashir U, Siddique MM, Mclean E, Goh V and Cook GJ: Imaging heterogeneity in lung cancer: Techniques, applications, and challenges. AJR Am J Roentgenol 207: 534-543, 2016.

8. Obulkasim A, Ylstra B, van Essen HF, Benner C, Stenning S, Langley R, Allum W, Cunningham D, Inam I, Hewitt LC, et al: Reduced genomic tumor heterogeneity after neoadjuvant chemotherapy is related to favorable outcome in patients with esophageal adenocarcinoma. Oncotarget 7: 44084-44095, 2016.

9. Cao W, Wu W, Yan M, Tian F, Liu HS, Wang JW, Zhang QW Li YJ and Li M: Multiregion sequencing reveals intratumor heterogeneity in esophageal squamous cell carcinoma. Zhonghua Zhong Liu Za Zhi 38: 660-666, 2016 (In Chinese).

10. Chen LQ, Hu CY, Ghadirian P and Duranceau A: Early detection of esophageal squamous cell carcinoma and its effects on therapy: An overview. Dis Esophagus 12: 161-167, 1999.

11. Schweigert M, Dubecz A and Stein HJ: Oesophageal cancer-an overview. Nat Rev Gastroenterol Hepatol 10: 230-244, 2013.

12. Spalding K, Board R, Dawson T, Jenkinson MD and Baker MJ: A review of novel analytical diagnostics for liquid biopsies: Spectroscopic and spectrometric serum profiling of primary and secondary brain tumors. Brain Behav 6: e00502, 2016.

13. Xie X, Jiang Y, Yuan Y, Wang P, Li X, Chen F, Sun C, Zhao H, Zeng X, Jiang L, et al: MALDI imaging reveals NCOA7 as a potential biomarker in oral squamous cell carcinoma arising from oral submucous fibrosis. Oncotarget 7: 59987-60004, 2016.

14. Potjer TP, Mertens BJ, Nicolardi S, van der Burgt YE, Bonsing BA, Mesker WE, Tollenaar RA and Vasen HF: Application of a serum protein signature for pancreatic cancer to separate cases from controls in a pancreatic surveillance cohort. Transl Oncol 9: 242-247, 2016.

15. Ren J, Zhang D, Liu Y, Zhang R, Fang H, Guo S, Zhou D, Zhang M, Xu Y, Qiu L and Li Z: Simultaneous quantification of serum nonesterified and esterified fatty acids as potential biomarkers to differentiate benign lung diseases from lung cancer. Sci Rep 6: 34201, 2016.
16. Jia K, Li W, Wang F, Qu H, Qiao Y, Zhou L, Sun Y, Ma Q and Zhao X: Novel circulating peptide biomarkers for esophageal squamous cell carcinoma revealed by a magnetic bead-based MALDI-TOFMS assay. Oncotarget 7: 23569-23580, 2016.

17. Wang S, Chen X, Luan H, Gao D, Lin S, Cai Z, Liu J, Liu H and Jiang Y: Matrix-assisted laser desorption/ionization mass spectrometry imaging of cell cultures for the lipidomic analysis of potential lipid markers in human breast cancer invasion. Rapid Commun Mass Spectrom 30: 533-542, 2016.

18. Kawaguchi-Sakita N, Kaneshiro-Nakagawa K, Kawashima M, Sugimoto M, Tokiwa M, Suzuki E, Kajihara S, Fujita Y, Iwamoto S, Tanaka K and Toi M: Serum immunoglobulin G $\mathrm{Fc}$ region $\mathrm{N}$-glycosylation profiling by matrix-assisted laser desorption/ionization mass spectrometry can distinguish breast cancer patients from cancer-free controls. Biochem Biophys Res Commun 469: 1140-1145, 2016.

19. Zhao J, Fan YX, Yang Y, Liu DL, Wu K, Wen FB, Zhang CY, Zhu DY and Zhao S: Identification of potential plasma biomarkers for esophageal squamous cell carcinoma by a proteomic method. Int J Clin Exp Pathol 8: 1535-1544, 2015.

20. Schwacke J, Millar TP, Hammond CE, Saha A, Hoffman BJ, Romagnuolo J, Hill EG and Smolka AJ: Discrimination of normal and esophageal cancer plasma proteomes by MALDI-TOF mass spectrometry. Dig Dis Sci 60: 1645-1654, 2015.

21. Fan NJ, Gao CF and Wang XL: Tubulin beta chain, filamin A alpha isoform 1 , and cytochrome b-cl complex subunit 1 as serological diagnostic biomarkers of esophageal squamous cell carcinoma: A proteomics study. OMICS 17: 215-223, 2013.

22. Zhai XH, Yu JK, Lin C, Wang LD and Zheng S: Combining proteomics, serum biomarkers and bioinformatics to discriminate between esophageal squamous cell carcinoma and pre-cancerous lesion. J Zhejiang Univ Sci B 13: 964-971, 2012.

23. Weiner LM, Surana R and Wang S: Monoclonal antibodies: Versatile platforms for cancer immunotherapy. Nat Rev Immunol 10: 317-327, 2010.

24. Rutkowski MJ, Sughrue ME, Kane AJ, Mills SA and Parsa AT: Cancer and the complement cascade. Mol Cancer Res 8: 1453-1465, 2010

25. Sliwkowski MX and Mellman I: Antibody therapeutics in cancer. Science 341: 1192-1198, 2013.

26. Taylor RP and Lindorfer MA: The role of complement in mAb-based therapies of cancer. Methods 65: 18-27, 2014.

27. Baig NA, Taylor RP, Lindorfer MA, Church AK, LaPlant BR, Pettinger AM, Shanafelt TD, Nowakowski GS and Zent CS: Induced resistance to ofatumumab-mediated cell clearance mechanisms, including complement-dependent cytotoxicity, in chronic lymphocytic leukemia. J Immunol 192: 1620-1629, 2014.

28. Markiewski MM, DeAngelis RA, Benencia F, Ricklin-Lichtsteiner SK, Koutoulaki A, Gerard C, Coukos G and Lambris JD: Modulation of the antitumor immune response by complement. Nat Immunol 9: 1225-1235, 2008.

29. Khan MA, Assiri AM and Broering DC: Complement and macrophage crosstalk during process of angiogenesis in tumor progression. J Biomed Sci 22: 58, 2015.

30. Sayegh ET, Bloch O and Parsa AT: Complement anaphylatoxins as immune regulators in cancer. Cancer Med 3: 747-758, 2014.

31. Denko NC, Fontana LA, Hudson KM, Sutphin PD, Raychaudhuri S, Altman R and Giaccia AJ: Investigating hypoxic tumor physiology through gene expression patterns. Oncogene 22: 5907-5914, 2003 